\title{
INDIVIDUALISMO MODERNO E SOFRIMENTO PSÍQUICO: uma análise da comunidade virtual dos neuróticos anônimos ${ }^{1}$
}

\author{
MODERN INDIVIDUALISM AND PSYCHIC SUFFERING: \\ analysis of an Anonymous Neurotic Virtual Community
}

Idayane Gonçalves Soares*

\begin{abstract}
Resumo
O artigo visa discutir a relação entre sofrimento psíquico e individualismo na sociedade moderna, dentro de um contexto teórico-metodológico da antropologia e da sociologia das emoções, a partir da análise qualitativa - com o emprego do método da etnografia virtual - de narrativas presentes no Fórum de Mensagens existente no grupo online "Caminho Novo", criado pela Irmandade de Neuróticos Anônimos (NA). O eixo de sua abordagem prioriza as experiências vividas por indivíduos em situação de sofrimento psíquico em um ambiente virtual de ajuda mútua. Nesse, encontra-se um caleidoscópio de narrativas com diversas experiências emocionais singulares que foram analisadas em seus conteúdos e sentidos sociais. Os resultados da pesquisa revelaram que a imersão no mundo sob uma nova orientação individualista tem íntima relação com os sofrimentos psíquicos que perpassam os depoimentos dos integrantes do Grupo de Ajuda Mútua de Neuróticos Anônimos (NA).
\end{abstract}

Palavras-chave: sofrimento psíquico, individualismo, Neuróticos Anônimos, cultura urbana.

\begin{abstract}
The article aims to discuss the relationship between psychic suffering and individualism in modern society from a theoretical-methodological approach based on Anthropology and Sociology of Emotions. We employ qualitative analysis - the method of virtual ethnography - focusing on narratives within the online group "Caminho Novo" created by the brotherhood Neurotics Anonymous (N/A). Our approach prioritizes the lived experience of individuals in situations of psychic suffering taking place in a virtual environment of mutual aid. In this environment, we encounter a kaleidoscope of narratives constituted by several emotional experiences analyzed in their content and social meaning. The research results revealed that the social world, characterized by a new individualistic orientation, is intimately related to psychic suffering that permeates the testimonies of the Mutual Aid Group Anonymous Neurotics (N/A).
\end{abstract}

Keywords: psychic suffering, individualism, Neurotics Anonymous, urban culture.

\footnotetext{
${ }^{1}$ Este artigo se originou da monografia: Individualismo moderno e sofrimento psíquico: uma análise da comunidade virtual dos Neuróticos Anônimos (SOARES, 2020), defendida no Curso de Ciências Sociais da UFPB no ano de 2020, sob orientação do professor Dr. Mauro Guilherme Pinheiro Koury, vencedora do Prêmio Honorífico de Monografias "Florestan Fernandes, edição 2020.

* Mestranda do Programa de Pós-graduação em Sociologia pela Universidade Federal da Paraíba (UFPB)/Brasil. E-mail: idayane_soares@hotmail.com.
} 
Dedicado ao professor Mauro Guilherme Pinheiro Koury, sem o qual esse trabalho não seria possível; em sua memória.

\section{Introdução}

Dar sentido ao sofrimento humano conforma um eixo fundamental da organização das culturas (FERREIRA, 2014), como um processo multifacetado e complexo e que tem tomado diferentes dimensões e sentidos ao longo da história. Posto que diferentes tempos e sociedades produzem certos tipos de sofrimento, eles não podem ser apreendidos estritamente pelas dimensões físicas e psicológicas: precisam ser observados com uma lente apropriada "para olhar as relações profundas entre a experiência subjetiva do malestar e os processos históricos e sociais mais amplos" (PUSSETTI; BRAZZABENI, 2011, p. 468).

Com a crescente "medicalização das emoções"2 e o silenciamento do sofrimento (FERREIRA, 2014) no mundo contemporâneo, onde o sofrer aparece sem sentido em relação ao seu caráter existencial, estudar o sofrimento psíquico e os seus sentidos sociais no âmbito da sociologia, da antropologia e da ciência política torna-se crucial nesse contexto atual na medida em que o mal-estar não pode ser observado e explicado independentemente das dinâmicas sociais que o suscitam, sendo um fenômeno circunstanciado.

Os sofrimentos psíquicos contemporâneos são abordados nas ciências sociais como uma subcategoria analítica do conceito mais amplo de sofrimento social. Eles são compreendidos, desse modo, como produtos de amplos processos históricos (econômicos, sociais, políticos, culturais) que desembocaram em novos arranjos da individualidade na contemporaneidade, e foram enquadrados no quadro das patologias.

\footnotetext{
${ }^{2}$ Refere-se ao processo de inibir as emoções através de psicofármacos ou de tratar "problemas emocionais" em termos de disfunções químicas e de negligenciar o tecido subjetivo que singulariza a especificidade da pessoa (EHRENBERG, 2004); trata-se de uma subsunção do sofrimento à dor psíquica passível de eliminação pelo uso de psicotrópicos (PERRUSI, 2015), de modo que o sofrimento é esvaziado de seu conteúdo e nada mais comunica.
} 
À luz da concepção de que cada época histórica tem seus sofrimentos psíquicos, os novos sofrimentos contemporâneos, que implicam também a existência de novas psicopatologias - dado o caráter também historicamente variável do que é enquadrado como psicopatológico —, atentam para a necessidade de se voltar as lentes para as transformações sociais mais amplas que estão intimamente atreladas às mudanças na individualidade e na formação psíquica dos indivíduos (PERRUSI, 2015).

Nesse debate sobre as novas configurações da individualidade e suas interrelações com os sofrimentos psíquicos, o(s) individualismo(s) aparecem como chave analítica importante para se compreender as tensões do indivíduo moderno. O individualismo contemporâneo aparece como dimensão fundamental de uma cultura urbana (VELHO, 2000), dada a relação bastante próxima existente entre o processo de urbanização das sociedades e o desenvolvimento das ideologias individualistas, para além de outros fenômenos substanciais correlacionados como a expansão do capitalismo. Isso pode, assim, ser analisado como configurando três movimentos interconectados: o capitalismo, o individualismo moderno e a urbanização.

Este artigo tem como objetivo discutir a relação entre sofrimento psíquico e individualismo na sociedade moderna, dentro do contexto teórico-metodológico da antropologia e da sociologia das emoções ${ }^{3}$, a partir da análise qualitativa de narrativas presentes no Fórum de Mensagens existente no grupo online "Caminho Novo", criado pela Irmandade de Neuróticos Anônimos (NA). Ela funciona como lócus (presencial e virtual) onde indivíduos interessados em participar e autodiagnosticados como neuróticos podem se ajudar, mutuamente, a resolver seus problemas emocionais comuns e se reabilitarem da "doença mental e emocional"4. O fórum, em especial, se constitui como um espaço virtual onde os inscritos podem compartilhar a qualquer hora experiências com os demais em relação a seu sofrimento e ao processo de fortalecimento pessoal por meio da aplicação do programa de NA.

Durante seis meses, foram lidos depoimentos desta comunidade em uma faixa temporal que segue o seu surgimento em 2009 até o início de 2020. Eles constituíam, até o período pesquisado, cerca de seis mil e seiscentos depoimentos. A metodologia utilizada

\footnotetext{
${ }^{3}$ Ver sobre a antropologia e a sociologia das emoções como campo teórico-metodológico e disciplinar, entre outros, Koury (2009) e Rezende; Coelho (2010).

${ }^{4}$ Assim colocada pelo grupo.
} 
seguiu a perspectiva qualitativa, e empregou o método da netnografia ou etnografia virtual que consiste em "pesquisa observacional participante baseada em trabalho de campo online" (KOZINETS, 2014, p. 61-2), e cujo espectro vai desde uma participação ativa até a observação silenciosa nos grupos pesquisados, garantindo procedimentos éticos.

Os grupos de ajuda mútua foram escolhidos por serem uma forma de organização que aponta para transformações profundas nas sociedades contemporâneas, posto que nelas "muito mais pessoas pertencem a grupos de auto-ajuda [ou ajuda mútua] do que são membros de partidos políticos" (GIDDENS, 1994, p. 12), e para novas formas de compartilhamento de situações emocionais vividas no cotidiano, especialmente no âmbito virtual.

O eixo da abordagem se encontra na tentativa de compreender experiências vividas por indivíduos em situação de sofrimento psíquico em um ambiente virtual de ajuda mútua. Nele, encontra-se um caleidoscópio de narrativas com diversas experiências emocionais singulares que foram analisadas em seus conteúdos e sentidos sociais. A pesquisa teve como chave-analítica o individualismo contemporâneo como dimensão fundamental de uma cultura urbana; junto com o fenômeno do capitalismo, ambos são basilares para se compreender as tensões do indivíduo moderno. Parte-se da hipótese compreensiva de que a imersão no mundo sob uma nova orientação individualista teria íntima relação com os sofrimentos psíquicos, entendidos aqui como uma subcategoria analítica do conceito mais amplo de sofrimento social, que perpassam os depoimentos dos integrantes do Grupo de Ajuda Mútua de Neuróticos Anônimos (NA).

Este artigo pretende, assim, enveredar pela relação complexa entre sofrimento psíquico e individualidade na sociedade contemporânea a partir da análise dos discursos presentes no espaço virtual citado.

\section{Sofrimento psíquico no espaço virtual de Neuróticos Anônimos (NA)}

Os sofrimentos psíquicos nas ciências sociais, e em especial, na antropologia e sociologia das emoções, são apreendidos como uma subcategoria do conceito mais amplo de sofrimento social, ou seja, como o resultado de danos devastadores que a força social 
inflige à experiência humana (KLEINMAN; DAS; LOCK, 1997). ${ }^{5}$ No caso aqui analisado, as novas configurações da individualidade mobilizadas nas sociedades complexas.

Com a complexidade que perpassa as transformações em quase todas as fases da vida social trazidas pela urbanização do mundo (WIRTH, 1967), vão surgindo trabalhos sociológicos e antropológicos que tomam a cidade e a realidade urbana enquanto objeto de pesquisa a partir do final do século XIX e início do século XX. Georg Simmel (1967; 1998) foi um dos primeiros a teorizar sobre o impacto da vida moderna na transformação da subjetividade dos indivíduos nas grandes cidades, e como elas influenciam na vida mental das pessoas. Logo após, influenciados pela perspectiva teórica simmeliana, os integrantes da Escola de Chicago construíram uma teoria sociopsicológica do urbanismo que aborda o modo de vida e de relações intersubjetivas nas metrópoles a partir da ótica da impessoalidade e da racionalidade (PARK, 1967; WIRTH, 1967).

Esses teóricos procuraram apresentar a cidade enquanto um mosaico de mundos sociais e as modificações que operam sobre o caráter das relações sociais. Os estudos sobre a cidade norte-americana de Chicago serviram de laboratório para a análise das grandes transformações que estavam ocorrendo a partir da lógica da modernização e crescimento urbano local. Assim, por um lado, notaram e analisaram o indivíduo citadino que, se teria ganho em margem de autonomia, liberdades individuais e desprendimento de controles pessoais e emocionais de grupos íntimos, teria perdido, por outro lado, em certo grau, o senso de participação comunitária e integração moral, sofrendo então um enfraquecimento nos vínculos sociais duradouros (WIRTH, 1967).

Partindo do princípio de que as configurações do(s) individualismo(s) provocam efeitos subjetivos e repercussões psíquicas nos indivíduos, se poderia aventar a existência de novas formas de sentir e de sofrer atreladas aos novos arranjos da individualidade contemporânea, os quais aparecem enquanto dimensão de uma cultura urbana, denotando uma subjetividade caracterizada pela internalização do sofrimento, privatização das emoções, distanciamento e indiferença, além de uma cultura emotiva específica que emerge como produto das transformações advindas da modernidade, caracterizada pelo

\footnotetext{
5 Tradução livre de: "an assemblage of human problems that have their origins and consequences in the devastating injuries that social force can inflict on human experience." (KLEINMAN; DAS; LOCK, 1977, p. IX).
} 
esgarçamento dos laços, fragmentação das relações sociais (KOURY 2001; 2003; 2005; 2008), e a própria carência de vínculos.

É essa relação tensa que, de certo modo, se apresenta no Fórum de Mensagens virtual da Irmandade de Neuróticos Anônimos (NA) ${ }^{6}$ analisado neste trabalho, isto é, como um mal-estar diante da falta de vínculos, da solidão, do isolamento, das interações travadas dentro de uma ótica impessoal, como explicam os membros de NA nos depoimentos abaixo:

[...] não tenho nenhum amigo na cidade onde moro atualmente. Ninguém para conversar. Mas achei que escrever me aliviaria um pouco. Não sei se é permitido, mas se alguém quiser me escrever pra conversar, posso passar meu e-mail. Paz a todos (informação verbal). ${ }^{7}$

Procurei uma reunião para ir, mas não encontrei aqui na minha cidade. Eu preciso de ajuda de conversar. O peso do Mundo está sob mim e eu desabando. Sinto que vou morrer a qualquer segundo (informação verbal). ${ }^{8}$

Luan indica que não há o grupo presencial de NA em sua cidade, o que também é citado de modo expressivo por outros usuários que se utilizam desse espaço virtual. Assim sendo, o espaço virtual dos NA é usado como forma de suprir a lacuna da não presença dos grupos presenciais em várias cidades brasileiras. O que, de um lado, amplia a rede NA atingindo uma grande parcela de pessoas que ficariam de fora do seu núcleo. E, de outro lado, permite a pessoas em situação de sofrimento psíquico poderem falar (escrever) sobre seus sofrimentos, dado que o depoente afirma necessitar "de ajuda de conversar". Como Ricardo assentou, sem o Fórum de Mensagens virtual ele não teria ninguém para conversar na cidade que mora atualmente.

Luciana, em seu depoimento, por sua vez, elucida bem a ideia contida na discussão simmeliana:

Meu objetivo é me mudar para uma cidade pequena, preferencialmente de clima mais ameno, onde possa passar a minha velhice em um ambiente mais humano. Cansei da grande metrópole. Gostaria de abrir uma sala de N/A nessa

\footnotetext{
${ }^{6} \mathrm{O}$ grupo Neuróticos Anônimos (NA) se apresenta como uma Irmandade voluntária formada por homens e mulheres que compartilham suas experiências para resolverem seus problemas emocionais comuns e se reabilitarem dos sofrimentos psíquicos aos quais se encontram submetidos. Na visão êmica do grupo, "neurótica é qualquer pessoa cujas emoções interferem em seu comportamento, de qualquer forma e em qualquer grau, segundo ela mesma o reconheça" e, para ser membro, basta a autopercepção como neurótico/a o desejo de se recuperar e, em seguida, a busca por ajuda com algum grupo de NA presente em todas as regiões do país e em diversos lugares do mundo.

${ }^{7}$ Ricardo, depoente do FM. Os nomes são fictícios. Todos os depoimentos citados foram retirados do fórum: https://groups.google.com/g/caminho-novo, em janeiro de 2020, e foram reproduzidos neste artigo foram transcritos sem modificações.

${ }^{8}$ Luan, depoente do FM.
} 
cidade pequena, caso ainda não houvesse uma. Frequentar a minha religião e, acima de tudo, procurar ter um convívio mais próximo das pessoas (informação verbal). ${ }^{9}$

Assim, ao dizer-se cansada da metrópole, ou do impacto desta na vida mental e emocional de seus habitantes, Luciana explica que deseja ter um convívio mais próximo das pessoas e viver em um ambiente "mais humano", ou mais pessoalizado. O seu depoimento, assim, vem como um reforço à hipótese central deste trabalho e dos achados analíticos dos autores supracitados da Escola de Chicago, de que as relações no individualismo urbano, do mesmo modo que possibilitam libertar-se de relações engolfadas ${ }^{10}$ (SCHEFF, 2016), também seriam causadoras de mal-estar e sofrimento para alguns.

Nas sociedades contemporâneas, o individualismo parece pesar a balança para o lado do "Eu" em detrimento do "Nós", como ponderou Norbert Elias (1994). E, nessa mudança de peso, tende a ocasionar uma incompreensão em torno dessa relação, levando o indivíduo a abrandar e quase apagar a presença do "Nós" em sua própria configuração individual, o que causa sofrimento social e psíquico, já que a balança eu-nós, na análise eliasiana, é completamente indissociável e interdependente das relações intersubjetivas dos indivíduos que dela fazem parte.

Do mesmo modo, causa medo e estranhamento em relação ao outro individual e coletivo (a multidão, por exemplo), debilitando a rede de relacionamentos. $\mathrm{O}$ voltar-se para dentro de si e o aumento exagerado do si mesmo são vistos aqui como universo e motivos para a ação, em que o indivíduo é isolado dos outros (SCHEFF, 2016), gerando um aprofundamento da dor individual e do sofrimento social sentidos como solidão, medo do fracasso, necessidade de conversar e ter receio de se abrir, aumento do pânico social e do sentimento de depressão continuada etc.

Elias explica que o processo de individualização crescente teria levado ao encapsulamento das relações entre os indivíduos e ao isolamento, produzindo o que ele chama de homo clausus. Isto é, nesse processo, o "Eu" desprovido do "Nós" é fruto da autoconsciência moderna, e se apresenta a si e ao outro como um indivíduo fechado em si mesmo, sem relação com a alteridade, independente. O estudo de Durkheim sobre o

\footnotetext{
${ }^{9}$ Luciana, depoente do FM.

${ }^{10}$ Noção de Thomas Scheff (1990), concernente a relações de intensa pessoalidade.
} 
suicídio, como indica Thomas Scheff, elucida bem essa ideia, que "Durkheim chama de egoísmo (independência) e altruísmo (dependência): grupos em que os relacionamentos são demasiadamente orientados em direção ao ego (o Eu-próprio) ou exageradamente orientados no sentido da conformidade com o grupo (o Nós-próprio)" (SCHEFF, 2016, p. 119).

Assim, com o processo de individualização crescente e a incompreensão que se avulta em torno dele, se desenvolve cada vez mais o aumento sobre o controle geral dos afetos e a privatização das emoções. A ideia de processo civilizador de Norbert Elias e de "ofensiva civilizadora" (REGT, 2017, p. 150-1) ${ }^{11}$ reajustados para as transformações das sociedades contemporâneas, conformam uma perspectiva interessante para se refletir sobre o grupo NA aqui analisado, dada a configuração da Irmandade, de incutir um maior autocontrole aos seus membros que sofrem de uma certa "impotência" para lidar com as suas emoções. Vide ${ }^{12}$, nesse sentido, o primeiro passo do programa dos Doze Passos dos Neuróticos Anônimos: “Admitimos que éramos impotentes perante nossas emoções - que tínhamos perdido o domínio sobre nossas vidas" e o lema do grupo: "Só por hoje evitarei o descontrole emocional."

A questão do autocontrole das emoções é uma perspectiva bastante evocada no discurso oficial de NA, que se coloca como uma associação que procura ajudar seus membros no controle e administração das emoções que despontam como elementos disruptivos em suas vidas. De modo simultâneo, essa perspectiva também aparece no espaço virtual, que se encontra repleto da abordagem das emoções como o item principal a ser trabalhado e que interfere no comportamento dos indivíduos.

No espaço virtual, esse tema é recorrente entre os depoentes. Está presente na totalidade (ou quase) das narrativas que expressam o descontentamento no fato de não terem suas emoções sob controle e pelas ingerências que elas acarretam em suas vidas.

Como pode ser visto nos relatos de usuários do espaço virtual aqui analisado ${ }^{13}$ :

De fato, não é fácil termos nossas emoções sob controle! Nosso emocional é como um cavalo selvagem que tentamos domar! Às vezes, acreditamos que estamos com ele firme nas rédeas, mesmo que isso nos exija grande

\footnotetext{
${ }^{11}$ Relativa às intervenções na vida de certos grupos, com o objetivo de incutir maior autocontrole (REGT, 2017).

12 Site: https://neuroticosanonimos.org.br/2010/10/20/os-12-passos-de-neuroticos-anonimos/.

${ }^{13}$ Os trechos grifados expressam com ênfase a questão do controle das emoções.
} 
esforço, como se fosse físico mesmo, afinal o cavalo é arredio! (informação verbal). ${ }^{14}$

[...] Tenho a convicção de que a minha incapacidade em controlar as minhas emoções é a guerra que enfrento sozinho desde criança. Vejo minha carreira se prejudicar em diversos momentos devido crises de ansiedade, medo entre outras que esporadicamente me tomam por completo. Sei que possuo um potencial e até tenho clientes satisfeitos com minha atuação, mas em alguns casos minha situação emocional me causa fracassos que mesmo sabendo que podem acontecer não consigo encontrar forças para enfrentar... (informação verbal). ${ }^{15}$

Minhas emoç̃es mudam muito rápido todos os dias. Tenho vergonha de ser assim, e me afasto. Nunca falei aos meus pais e finjo o máximo que está sempre tudo bem, mas a maioria eu fico sozinha no meu quarto. Me sinto culpada, e não sei o que fazer. Preciso de ajuda. (informação verbal). ${ }^{16}$

Sinto vergonha e medo de nunca ter controle sobre minhas fraquezas. Não consigo parar de chorar e só queria ser esquecido por uns dias, pelo mundo. Obrigado N/A por tudo, ler os relatos de vocês sempre me faz entender que não sou um monstro e que não estou sozinho. (informação verbal). ${ }^{17}$

Nesse sentido, conforme Koury e Barbosa (2016, p. 13), o argumento de Scheff de que "o processo civilizador se organizou de forma a consolidar uma cultura emotiva de repressão da vergonha e de invisibilização de signos de fracasso e falência individual", torna mais claro o entendimento das narrativas acima citadas que colocam o medo do fracasso, a dificuldade em "domar" as emoções - que aparecem em seus depoimentos - como elemento disruptivo e como vergonha de seu descontrole.

O que indica a perspectiva de que "o self ocidental opera em uma espiral de vergonha da vergonha e de privatização das emoções e da subjetividade" (KOURY; BARBOSA, 2016, p. 14). O avanço no autocontrole e nesse limiar da vergonha faz com que esses atores sintam imenso desconforto quando no jogo interacional se veem diante do que é considerado um "descontrole emocional". Ao pesquisar a palavra vergonha no Fórum de Mensagens, percebe-se o quanto essa emoção é importante na construção da sociabilidade dos usuários que expressam recorrentemente a vergonha de sentir o que sentem, a vergonha do fracasso (GOFFMAN, 2014) ${ }^{18}$, a vergonha "como um medo social em relação a uma ameaça de rompimento de um vínculo social determinado" (KOURY;

BARBOSA, 2016, p. 17).

\footnotetext{
${ }^{14}$ Edmundo, depoente do FM.

${ }^{15}$ Rafael, depoente do FM.

${ }^{16}$ Luana, depoente do FM.

17 Júlio, depoente do FM.

${ }^{18}$ Sobre a análise do fracasso na obra de Goffman, ver Koury (2019).
} 
De tal modo, compreendendo a vergonha e o medo a partir da antropologia e da sociologia das emoções como "uma teia de sentimentos dirigidos diretamente a outros e causado pela interação com outros em um contexto e em uma situação social e cultural determinados," (KOURY, 2009, p. 84), e dados os processos que permeiam as interações, as narrativas coletadas nos diversos depoimentos no Fórum de Mensagens virtual do grupo analisado parecem apontar para a tese de que em uma sociabilidade perpassada pela ideologia do individualismo, a vergonha e a interdependência são negadas e reprimidas, e se tornam tabus socais (KOURY; BARBOSA, 2016) silenciados na modernidade. No Fórum de Mensagens, a vergonha é colocada como mal-estar por estar imersa em códigos mais individualistas de intersubjetividade e de autopercepção e, por "ser assim", como expressa Tamires:

[...] E, resumindo a história porque se continuar assim vira livro, tenho esses problemas até hoje, tenho 29 anos... não consigo ter um convívio social saudável, não tenho amigos de longa data, são sempre novos e recentes e só duram até eu chegar no meu limite e me afastar deles... é muito triste isso e morro de vergonha de ser assim, mas ainda não consegui mudar isso em mim. (informação verbal). ${ }^{19}$

Tamires informa que não consegue ter um convívio social saudável, que não tem amigos de longa data, e os que ela possui são sempre novos e recentes e não duram muito, logo chegando ao limite e se afastando deles. O que indica que o lema "não há longo prazo" é típico de sociedades permeadas pelo individualismo moderno como dimensão de uma cultura urbana, atravessando a flutuação de amizades - como informada pela depoente —, ou as flutuações e a precariedade das relações de trabalho - como analisado no livro A corrosão do caráter, de Sennett (2009) —, e os vários âmbitos da vida dos indivíduos. Essas flutuações e precariedades são práticas constantes no ir e vir das cidades contemporâneas. E os mal-estares são próprios das mudanças que vêm se operando na sociedade ocidental, e brasileira particularmente, nas últimas décadas. Tamires, então, sente vergonha de sentir-se assim, posto que se sente e se entende como sozinha em suas emoções.

Essa autoconsciência moderna obsta assim o entendimento de que a vergonha implica ver a si mesmo do ponto de vista dos outros, em que o "Nós" da constituição individual funciona como um giroscópio moral e, assim, "o constrangimento e o

\footnotetext{
19 Tamires, depoente do FM.
} 
embaraço próprios da copresença são processados como um enorme desconforto a ser manejado pelo ator social engajado em amplas cadeias de interdependência e em situações de desorganização normativa" (KOURY; BARBOSA, 2016, p. 14). Uma depoente expressa de maneira singular o desconforto da copresença que precisa ser manejada pelos atores:

Hoje sei com absoluta certeza que eu vivo como se eu estivesse amarrada a um elástico... que me faz subir e despencar conforme me sinto querida pelas outras pessoas ou conforme me sinto abandonadas por ela. Horrível e sem sentido viver assim. Uma hora quero fazer tanta coisa... outra hora quero morrer. Leio os relatos às vezes ... e fico pensando... quanto sofrimento por todos os lados... por que tantos desencontros? (informação verbal). ${ }^{20}$

A tese de se viver como amarrado a um elástico que a faz subir ou despencar conforme o caráter das relações estabelecidas com os outros mostra o impacto que têm as interações entre os indivíduos em seus cotidianos, para além da própria formação emocional e individual a partir do 'Nós', como colocou Elias. Interações e vínculos afetivos calcados em códigos mais individualistas de intersubjetividade e autopercepção causam sofrimentos psíquicos por todos os lados como informa a depoente, e, do mesmo modo, muitos desencontros, no sentido do destecer constante dos vínculos com os outros e, de forma ambivalente, do sentimento de falta do outro ou do encontro com um outro imaginário que a preencha e a acolha como pessoa, aumentando a dor social e individual pela carência de vínculos e não saber como chegar ao outro ou ter receio de ser usada ou passada para trás. Conforme Scheff (2016, p. 181), a partir de Charles Cooley, a intersubjetividade tem sido tão naturalizada até o ponto de sua invisibilidade, que muitas pessoas mal percebem que se preocupam com o monitoramento e o julgamento do outro, de modo que quando se abatem pela falência ou pela desgraça, percebem logo que estavam vivendo na mente dos outros sem o perceber.

Como informa Mead (1972), a "persona" se origina a partir de um desenvolvimento que surge no processo da experiência e da atividade social, na relação do indivíduo com os outros. O desenvolvimento da autoconsciência ocorre a partir do social, e manifesta-se diversamente de acordo com cada situação específica, e assume diversos papéis nas relações entre os indivíduos. Assim, as personas só podem existir a

\footnotetext{
${ }^{20}$ Depoimento existente no Fórum de Mensagens de NA.
} 
partir de uma relação com as outras. Nesse sentido, o conto $O$ espelho de Machado de Assis (2010), que narra o caso de um protagonista quando se vê subitamente afastado e isolado dos vínculos sociais e não consegue mais ver a sua imagem refletida no espelho, demonstraria o papel que tem a alteridade na preservação das identidades individuais, além da sua própria formação pessoal e social.

Por sua vez, o indivíduo, ao se encontrar em um mundo imerso nos códigos mais individualistas que aparecem enquanto dimensão de uma cultura urbana e que denotam uma subjetividade caracterizada pela internalização do sofrimento, privatização das emoções, distanciamento, indiferença etc., e de uma cultura emotiva específica que emerge como produto das transformações advindas da modernidade, caracterizada pelo esgarçamento dos laços, fragmentação das relações sociais (KOURY, 2001; 2005; 2008) e pelo pujante isolamento, se vê ilhado. Enxerga-se solitário, com dificuldades e medos de inclusão e de vínculos com os outros. Ao mesmo tempo em que se avista como sendo dividido entre dois mundos (interior e exterior) como bem explicitou Elias (1994).

Jacobina, personagem do mencionado conto de Machado de Assis (2010, p. 33), apesar do dualismo existente em sua fala, explica que "cada criatura humana traz duas almas consigo: uma que olha de dentro para fora, outra que olha de fora para dentro...". Pensando eliasianamente, para o homo clausus há somente a primeira "alma", a do "eu" isolado, submerso no interior de um invólucro, incompreendido e incomunicável que olha de dentro para fora. Assim, essa concepção ou incompreensão em torno do processo de individualização já discorrido torna obscuro o fato de que, ainda que as aceitações passivas de toda conjunção de regras sociais tornem "inautêntica" a existência de um indivíduo, isso não se dá na realidade, pois os indivíduos não se encontram numa prisão lúgubre e determinista, mas em um palco com atores vivos como explana muito bem Berger (1972): deve-se cravar com letras de fogo que só é possível a "autenticidade" dentro da vida em sociedade. A individualidade só é possível para o indivíduo que cresce no seio social.

Visto em um determinado modo interpretativo, no caso o eliasiano (ELIAS, 1994) — sobre a individuação no processo social —, o indivíduo se apresenta, de um lado, imerso em um processo de individualização crescente do qual faz parte, e de outro lado, simultaneamente, de um processo civilizatório determinado. Dupla imersão que aparece 
nas reflexões individuais das pessoas como um vazio existencial entre um ser humano (a sua alma interior) e o outro 'eu' (as forças sociais que o impelem e dirigem sua vida através da relação externa do conjunto de papéis e status sociais), ou como o eterno choque entre indivíduo e sociedade (ELIAS, 1994).

Entretanto, para se compreender a totalidade da relação entre indivíduo e sociedade, que se apresentam como duas entidades ontologicamente diferentes em grande parte da sociologia, e superar o estabelecimento de impérios do sujeito ou do objeto, e o abismo mental que esse ardoroso embate valorativo compõe, Norbert Elias propõe voltar o olhar para o termo "rede" e o objeto de que deriva o conceito. Sendo a ideia de rede só compreensível em termos da maneira como os fios se ligam para a sua formação, e de sua relação recíproca. Elias indica, porém, que essa ideia pode vir a se tornar um modelo estático se a noção de rede não estiver contida em um processo.

Para ele, a relação pode ser mais bem entendida ao se imaginar a rede em constante movimento como um tecer e destecer ininterrupto de ligações (ELIAS, 1994). Essa abordagem coloca em foco o caráter processual e dinâmico das redes estabelecidas pelos indivíduos e a necessidade de modelos conceituais que permitam tornar compreensível o que é vivenciado diariamente na realidade cotidiana em jogo permanente entre indivíduos e grupos (ELIAS, 1994).

Dessarte, percebi que em NA, a leitura cotidiana das narrativas ou a escuta, o verse através do sofrimento de outros, ou o "enxergar que outras pessoas possam estar padecendo dos mesmos problemas que eu", o falar sobre o próprio sofrer e construir sentido em torno dele, o sentir-se responsável por qualquer um que peça ajuda e o fazer parte de uma comunidade cujos membros procuram ajudar-se mutuamente, contribui para o fortalecimento pessoal dos seus participantes, pois vai de encontro ao imperativo existente de negação do sofrimento e de sua medicalização em uma sociedade que demanda pessoas "habitualmente em um estado de bem-estar".

\section{Conclusão}

Os indivíduos, na agitação de suas experiências diárias, frequentemente se encontram limitados pelas órbitas privadas em que vivem, e circunscritos ao cenário mais próximo: o emprego, a família, o casamento, as suas relações afetivas. Habitualmente não 
definem suas ansiedades em termos de transformação histórica e contradição institucional, e raramente "têm consciência da complexa ligação entre suas vidas e o curso da história mundial; por isso, os homens comuns não sabem, quase sempre, o que essa ligação significa para os tipos de ser em que se estão transformando e para o tipo de evolução histórica de que podem participar” (MILLS, 1969, p. 10).

Os sofrimentos que vivenciam, experimentam-nos como uma falha ou fracasso individual sem conseguir visualizar as interrelações entre eles e a sociedade, o eu e o mundo, o sentido de sua época e suas próprias vidas. Não se compreende que este cotidiano vivido sob a sombra ameaçadora do fracasso, sempre constante e à espreita, tem íntimas relações com uma cultura do fracasso presente nas sociedades contemporâneas que coloca os seus cidadãos em cheque e transforma o encontro social em choque agonístico para seus membros (KOURY, 2019, p. 537).

A imaginação sociológica, como explica Mills (1969, p. 13-4), é “a capacidade de ir das mais impessoais e remotas transformações para as características mais íntimas do ser humano - e ver as relações entre as duas." É compreender que aquilo que experimentamos em diversos e específicos ambientes de pequena escala é com frequência causado pelas modificações estruturais, e que o indivíduo em seu ambiente limitado tem pouca margem de resolver sozinho — com ou sem ajuda psiquiátrica — os problemas que essa estrutura the cria (MILLS, 1969). Por isso, segundo Mills, a tarefa intelectual e política de um/a cientista social deve ser a de deixar claros os elementos de inquietação contemporânea.

Assim, procurou-se com este artigo apresentar as relações entre experiências emocionais singulares e os conteúdos e sentidos sociais presentes nelas, evidenciando, a partir do estudo das narrativas de sofrimento psíquico do Grupo de Ajuda Mútua de Neuróticos Anônimos (NA), que há uma relação bastante próxima entre o mal-estar sentido pelos depoentes e o individualismo contemporâneo que aparece como dimensão fundamental de uma cultura urbana, para além de outros fenômenos substanciais correlacionados, como a expansão do capitalismo.

Dentro desse contexto, com a disseminação de Grupos de Ajuda Mútua que lidam com alguns desses processos sociais, a Irmandade de Neuróticos Anônimos, apesar de suas ambiguidades e relações com o contexto específico de sua criação, possibilitou aos 
seus membros um caminho para a compreensão do seu sofrer, fornecendo um contraponto ao imperativo hodierno de seu silenciamento, bem como - por meio da comunhão entre participantes que sofrem e que buscam ajudar-se mutuamente - a "recuperação" gradual ou o fortalecimento pessoal. Dessarte, buscou-se promover um entendimento das realidades íntimas de indivíduos em ligação com realidades sociais mais amplas, procurando abarcar as modificações estruturais pelas quais passaram as sociedades modernas, destacando a transformação da subjetividade dos indivíduos nesses processos, apresentando como os indivíduos, em momentos que parecem ser os mais íntimos e solitários de suas vidas, encontram-se em um momento profundamente sociológico, enredados em teias que conectam seus sofrimentos a outros ao seu redor.

\section{Referências}

ASSIS, Machado de. Melhores contos. São Paulo: Global, 2010.

BERGER, Peter. Perspectivas sociológicas. Petrópolis: Vozes, 1972.

EHRENBERG, Alain. Depressão, doença da autonomia? [Entrevista concedida a Michel Botbol]. Ágora, Rio de Janeiro, v. 7, n. 1, p. 143-153, 2004. Disponível em: https://www.scielo.br/j/agora/a/wHfWfz3Gth3d6vCJZvrMhcw/?lang=pt. Acesso em: 11 out. 2021.

ELIAS, Norbert. A sociedade dos indivíduos. Rio de Janeiro: Zahar, 1994.

FERREIRA, Jonatas Ferreira. Sofrimento e silêncio: apontamentos sobre sofrimento psíquico e consumo de psicofármacos. Fórum Sociológico, Lisboa, n. 24, p. 121-128, 2014. Disponível em: https://journals.openedition.org/sociologico/1133. Acesso em: 11 out. 2021.

GIDDENS, Anthony. Admirável mundo novo: o novo contexto da política. Caderno CRH., Salvador, n. 21. p. 9-28, 1994. Disponível em: https://periodicos.ufba.br/index.php/crh/article/view/18771. Acesso em: 11 out. 2021.

GOFFMAN, Erving. Sobre o resfriamento do marca: alguns aspectos da adaptação ao fracasso. RBSE, João Pessoa, v. 13, n. 39, p. 266-283, 2014. Disponível em: http://www.cchla.ufpb.br/rbse/GoffmanKouryRes.pdf. Acesso em: 12 out. 2021.

KLEINMAN, Arthur.; DAS, Veena; LOCK, Margareth. Social suffering. Berkeley: University of California Press, 1997.

KOURY, Mauro Guilherme Pinheiro. Sobre Erving Goffman e a análise do fracasso em The Presentation of Self in Everyday Life. Dilemas - Revista de Estudos de Conflito e Controle Social, Rio de Janeiro, v. 12, n. 3, p. 525-540, 2019. Disponível em: https://revistas.ufrj.br/index.php/dilemas/article/view/24692/20891. Acesso em: 12 out. 2021.

KOURY, Mauro. Emoções, sociedade e cultura: a categoria de análise emoções como objeto de investigação na sociologia. Curitiba: Editora CRV, 2009. 
KOURY, Mauro Guilherme Pinheiro. De que João Pessoa tem Medo? Uma abordagem em Antropologia das Emoções. João Pessoa: Editora Universitária, 2008. Coleção Cadernos do GREM, n. 6.

KOURY, Mauro Guilherme Pinheiro. Amor e dor: ensaios em antropologia simbólica. Recife: Edições Bagaço, 2005.

KOURY, Mauro Guilherme Pinheiro. Sociologia da emoção: o Brasil urbano sob a ótica do luto. Petrópolis: Vozes, 2003.

KOURY, Mauro Guilherme Pinheiro. Ser discreto: um estudo do Brasil urbano sob a ótica do luto. João Pessoa: GREM/UFPB, 2001.

KOZINETS, Robert. V. Netnografia: realizando pesquisa etnográfica online. Porto Alegre: Penso, 2014.

MEAD, G.H. Espíritu, persona y sociedad. Buenos Aires: Paidós, 1972.

MILLS, Wright. A imaginação sociológica. Rio de Janeiro: Zahar Editores, 1969.

PARK, Robert. A cidade: sugestões para a investigação do comportamento humano no meio urbano. In: VELHO, Otávio. O fenômeno urbano. Rio de Janeiro: Zahar Editores, 1967. p. 25-66.

PERRUSI, Artur. Sofrimento psíquico, individualismo e uso de psicotrópicos: saúde mental e individualidade contemporânea. Tempo Social, São Paulo, v. 27, n. 1, p. 139-160, 2015. Disponível em: https://www.scielo.br/j/ts/a/RbtXH5FvNzT3w4RHC4wnHMq/abstract/?lang-pt. Acesso em: 11 out. 2021.

PUSSETTI, Chiara; BRAZZABENI, Micol. Sofrimento social: idiomas da exclusão e políticas do assistencialismo. Etnográfica, Lisboa, v. 15, n. 3, p. 467-478, 2011. Disponível em: https://journals.openedition.org/etnografica/1036. Acesso em: 11 out. 2021.

REGT, Ali de. Ofensiva civilizadora: do conceito sociológico ao apelo moral. RBSE, João Pessoa, v. 16, n. 47, p. 137-153, 2017. Disponível em: http://www.cchla.ufpb.br/rbse/DeRegtKoury ArtTrad.pdf. Acesso em: 12 out. 2021.

REZENDE, Claudia Barcellos; COELHO, Maria Claudia. Antropologia das emoções. Rio de Janeiro: Editora FGV, 2010.

SCHEFF, Thomas. Desvendando o processo civilizador: vergonha e integração na obra de Elias. In: KOURY, M. G. P.; BARBOSA, Raoni Borges. Vergonha no self e na sociedade: a sociologia e a antropologia das emoções de Thomas Scheff. Recife: Ed. Bagaço; João Pessoa: Edições do GREM, 2016. p. 111-138. Coleção Cadernos do GREM, n. 10.

SCHEFF, Thomas. Microsociology. Chicago: University of Chicago Press, 1990.

SENNETT, Richard. A corrosão do caráter: consequências pessoais do trabalho no novo capitalismo. Rio de Janeiro: Record, 2009.

SIMMEL, Georg. O indivíduo e a liberdade. In: SOUZA, Jessé; OELZE, Berthold. (org). Simmel e a modernidade. Brasília: Editora UnB, 1998. p. 109- 117.

SIMMEL, Georg. A metrópole e a vida mental. In: VELHO, Otávio. O fenômeno urbano. Rio de Janeiro: Zahar Editores, 1967. p. 10-25. 
SOARES, Idayane, Individualismo moderno e sofrimento psíquico: uma análise da comunidade virtual dos Neuróticos Anônimos. 2020. Trabalho de Conclusão de Curso (Bacharelado em Ciências Sociais) — Universidade Federal da Paraíba, João Pessoa, 2020.

VELHO, Gilberto. Individualismo, anonimato e violência na metrópole. Horizontes Antropológicos, Porto Alegre, n. 13, 2000. Disponível em: https://www.scielo.br/j/ha/a/PDQbgwGmqB7qZsgHcvCVphN/?lang-pt. Acesso em: 11 out. 2021.

WIRTH, Louis. O urbanismo como modo de vida. In: VELHO, Otávio. O fenômeno urbano. Rio de Janeiro: Zahar Editores, 1967. p. 89-112.

Recebido em: 04/09/21.

Aceito em: 11/10/21. 